\title{
O SOCIAL E SUAS DIMENSÕES EM AGROINDÚSTRIAS FAMILIARES RURAIS
}

\author{
Aline WeberSulzbacher ${ }^{1}$ \\ Pedro Selvino Neumann ${ }^{2}$
}

\section{Resumo}

A aproximação entre a temática da agroindustrialização e da avaliação de impacto social se faz necessária à medida que a atividade ganha respaldo diante das políticas públicas e, principalmente, dos agricultores enquanto uma estratégia de reprodução social. A fim de contribuir nesse debate e problematizar a relação entre agroindústria familiar e qualidade de vida, trabalhamos com a ideia de avaliação de impacto social. Temos por objetivo discutir sobre a dimensão social das agroindústrias na propriedade familiar, sobretudo a partir de algumas variáveis. A pesquisa contemplou uma análise teórica da temática de avaliação de impacto social; incursões empíricas para diálogo com agricultores e outros agentes locais, a fim de levantar variáveis e indicadores; e, por fim, uma síntese avaliativa da proposta e da dimensão social da agroindustrialização. De forma geral, concluímos que a agroindústria como o "carro-chefe" da unidade de produção gera um impacto considerável, porém pode comprometer a reprodução social. Observamos que, inevitavelmente, a opção pela transição para a agroindústria familiar implica investimentos, mudanças na lógica de trabalho e de gestão da unidade de produção agrícola e, com elas, algumas consequências indesejáveis, que passam muitas vezes despercebidas (ou não são discutidas) aos agentes envolvidos. Por fim, apontamos a necessidade de discussão sobre o perfil de agroindústria desejável às diferentes realidades rurais, e, sobretudo,

${ }^{1}$ Graduada em Geografia (UFSM), Mestre em Extensão Rural (UFSM), Especialista em Agricultura Familiar Camponesa e Educacãa do Campo (PRONERA/UFSM), Doutorado em Geografia (FCT/UNESP), Bolsista FAPESP/SP, email: sulzba@gmail.com

${ }^{2}$ Graduação em Agronomia (UFSM), Mestrado em Extensão Rural (UFSM), Doutor em Engenharia de Produção pela (UFSC), Prof. Adjunto Universidade Federal de Santa Maria (UFSM), email: neumannsp@yahoo.com.br 
faz-se fundamental começar a discutir e a considerar a dimensão social como um elemento essencial, uma vez que implica em sérias mudanças no modo de vida das famílias rurais.

Palavras-chave: Agricultura familiar, impacto social, política pública

\title{
THE HIDDEN SIDE OF THE RURAL FAMILIES AGRO-INDUSTRY: SOCIAL LEVEL AND ITS DIMENSIONS
}

\begin{abstract}
The rapprochement between the theme of agro-industry and social impact assessment is necessary as the activity gets support on public policy and especially of farmers as a strategy of social reproduction. In order to contribute to this debate and discuss the relationship between agro-industry and family quality of life, we work with the idea of social impact assessment. We aim to discuss on the social dimensions of family owned agro-industry, for that, we start of a thematic contextualization of evaluating the social impact, followed by an overview of principle aspects which are studied in the Rural Families Agro-Industry (AFR, in portuguese) to demonstrate the lack of studies of the social dimension of this industry. The research included a theoretical analysis of the issue of social impact assessment; empirical to dialogue with farmers and other local actors raids in order to raise variables and indicators; and finally, an evaluative summary of the proposal and the social dimension of industrialization. Overall, we conclude that the agricultural industry as the "flagship" of the production unit generates a considerable impact, but may undermine the social reproduction. We observed that, inevitably, the option to transition to AFR investments implies, changes in working logic and management of agricultural production unit, and with them, some undesirable consequences that often go unnoticed (or are not discussed) to agents involved. Finally, we point out the need for discussion about the desirable profile of the different rural realities agribusiness, and, above all, it is vital to begin to discuss and consider the social dimension as an essential element, since it involves serious changes in the way rural families.
\end{abstract}

Key-words: Framers, social dimensions, public policy 


\section{INTRODUÇÃO}

A aproximação entre a temática da agroindustrialização e da avaliação de impacto social se faz necessária à medida que a atividade vem ganhando respaldo diante das políticas públicas e, principalmente, dos agricultores enquanto uma estratégia de reprodução social. Nos discursos sobre a agricultura familiar rural (AFR), é comum sua livre associação com a ideia de agregação de valor, geração de empregos e renda. Nas experiências mais promissoras, ela promove a articulação dos sujeitos rurais, constituindo cooperativas de comercialização dos produtos das agroindústrias associada ${ }^{3}$, consolidando redes de produçãodistribuição-consumo e inserindo-se, inclusive, nas grandes redes de mercados - atendendo, portanto, às demandas contemporâneas colocadas pelo setor agroalimentar.

Observa-se, de modo geral, que, em municípios em que a AFR vem se fortalecendo, ocorrem variadas mudanças, principalmente quanto a melhorias na qualidade de vida dos sujeitos envolvidos. Há diferentes estudos de casos mostrando que a AFR promove uma série de impactos nas escalas da unidade de produção familiar e no entorno comunitário e que, em muitos casos, extrapolam as fronteiras regionais. Ainda assim, de modo geral, as ponderações são ora pontuais, ora genéricas, e não vislumbram uma discussão direcionada para a perspectiva de avaliar, efetivamente, o que significa "agregar valor, gerar emprego e renda" em termos de qualidade de vida da família rural.

Por outro lado, geralmente passam despercebidas aquelas experiências que se estagnaram no tempo. Ficam esquecidas ao olhar da ciência e dos extensionistas rurais (que, geralmente, são nossos informantes-chave e nos apresentam os casos mais representativos).

A fim de contribuir nesse debate e problematizar a relação entre agroindústria familiar e qualidade de vida, trabalhamos com a ideia de avaliação de impacto social. Geralmente, o campo sobre

\footnotetext{
${ }^{3}$ Um exemplo desse processo é a Unidade Central das Agroindústrias Familiares do Oeste Catarinense (UCAF), criada no final dos anos 1990, a qual fornece uma base de serviços de apoio, como assistência técnica, de contabilidade e de mercado (marketing, código de barras etc.) (MIOR, 2008).
} 
avaliação é caracterizado pela falta de consensos, com intermináveis discussões. Afinal, quais devem ser os critérios e como se deve mensurá-los? Avaliar exige construir parâmetros que tenham a capacidade de resguardar a transversalidade aos diferentes elementos e situações que se pretende comparar ou analisar. Toda avaliação tem por imperativo fornecer parâmetros confiáveis e comparáveis. Para tal, o ato de avaliar constitui-se como processo, e exige-se que seja capaz de captar as transformações, a começar com mecanismos para mensurar a evolução e gestar os resultados, tanto positivos quanto negativos. Avaliar é, antes de tudo, um modo de testar a eficácia das ações e rever métodos.

Dessa forma, apresentamos aqui uma discussão sobre a dimensão social do impacto da agroindústria familiar rural na propriedade familiar. Em específico, partimos de uma contextualização sobre a temática da avaliação de impacto social, seguida de uma síntese dos principais aspectos que são estudados no âmbito das AFRs, de modo a demonstrar algumas lacunas sobre a dimensão social da agroindustrialização. Na terceira sessão, apresentamos e contextualizamos algumas das variáveis que utilizamos para a avaliação de impacto social das agroindústrias que foram objeto de estudo.

Os aportes metodológicos deste artigo têm por base a pesquisa realizada em 2007 e 2008 para o desenvolvimento da dissertação de mestrado. Na oportunidade, realizou-se um estudo teórico acerca da avaliação de impacto social e, a partir desse suporte, construiu-se uma primeira proposta, com uma série de variáveis e indicadores, que foram aplicados em pesquisa de campo em seis AFRs e duas experiências de produção artesanal de alimentos no município de Constantina/RS. Por fim, a proposta de avaliação de impacto social foi reelaborada através da inclusão e/ou exclusão de variáveis, indicadores e hipóteses de impactos. Esse processo resultou em uma proposta de avaliação de impacto social que contempla 25 variáveis com 56 indicadores, envolvendo escalas da unidade de produção e do entorno comunitário.

\section{COMO VALORAR A DIMENSÃO SOCIAL NA AVALIAÇÃO DE IMPACTOS?}

Uma das primeiras considerações a serem destacadas é a concepção da "mudança social" como propulsora do "impacto social" e, estes, como frutos de projetos ou planos de intervenção. Vanclay 
(2002) faz alguns alertas no sentido de atentar para essa diferença basilar no processo de avaliação de impacto social, uma vez que muitas mudanças sociais, por si mesmas, não são impactos. Além disso, acrescenta que impactos sociais indiretos são resultantes de mudanças no ambiente biofísico, enquanto os impactos sociais diretos resultam daquele processo de mudança social que eleva o bem-estar social (VANCLAY, 2002, p. 191-193, tradução nossa). Nesse marco teórico, a:

Avaliação de Impacto Social é o processo de
análise (previsão, avaliação e reflexão) e
gestão das consequências intencionais e não
intencionais no ambiente humano fruto das
intervenções planejadas (políticas,
programas, planos, projetos), além de
qualquer processo de mudança social
envolvido com essas intervenções a fim de
trazer um ambiente humano mais sustentável
e equitativo biofisicamente (VANCLAY, 2002,
p. 388, tradução nossa).

Dentre as dificuldades para definir a dimensão social da avaliação de impacto, ressalta-se que é impossível identificar todos os processos de mudança social que poderiam acontecer em função de algum projeto versus aqueles que acontecem na sociedade. Outra questão é o avaliar com clareza o que seria processo de mudança social e o nível de detalhe, ou a escala de análise, a ser considerado (VANCLAY, 2002).

Além disso, existe uma significativa variedade de possibilidades e fatos que podem ser considerados impacto social. Nesse detalhe, concentra-se a dificuldade de estipular modelos, uma vez que, provavelmente, os impactos sociais significativos sofrem variação de lugar para lugar, de projeto para projeto, e o peso para cada impacto social variará de comunidade para comunidade e entre os diferentes grupos dentro de determinada comunidade (VANCLAY, 2002, p. 184, tradução nossa).

Algumas propostas vêm sendo elaboradas no sentido de definir categorias, indicadores e até matrizes de avaliação de impacto social. Elas se constituem como tentativas de suprimir deficiências ou lacunas em um campo de pesquisa muito vasto.

Vanclay (2002) discute a possibilidade de utilizar uma matriz de avaliação de impacto social e aponta duas perspectivas: uma 
favorável, já que essa matriz poderia ser utilizada para nortear as avaliações e contribuir com os investigadores que, em geral, têm subestimado os possíveis impactos sociais nas comunidades; noutra ótica, uma matriz poderia direcionar as respostas e não levantar o que realmente se passa na comunidade. Além disso, geralmente lists of social impacts consideram apenas os impactos negativos dos projetos, não levando em consideração os objetivos e benefícios alcançados.

O mesmo autor ressalta que impactos sociais podem se referir a variáveis com indicadores quantitativos, mas também àqueles qualitativos, tais quais: impactos culturais envolvendo mudanças nas normas da população, valores, convicções e percepções sobre a sociedade em que vivem (VANCLAY, 2002, p. 184-185, tradução nossa). Ele acrescenta que os especialistas em impacto social costumam destacar que é impossível detalhar todas as dimensões dos impactos sociais (mudanças sociais acabam gerando outras mudanças). Inevitavelmente, as mudanças sociais são dependentes de vários fatores, dentre eles o contexto social, econômico, político e cultural das comunidades envolvidas.

Vários cientistas sociais têm tentado criar uma tipologia de impactos sociais. Dentre as propostas, sistematizamos, no Quadro 1, as considerações de três autores sobre as variáveis e os indicadores que poderiam ser considerados.

Tabela 1 - Variáveis e indicadores de impacto social

\begin{tabular}{|c|c|c|}
\hline Aut. & Variáveis & Indicadores \\
\hline \multirow{3}{*}{$\begin{array}{l}\bar{\Phi} \\
\text { D } \\
\Phi \\
\Phi\end{array}$} & $\begin{array}{c}\text { Tipo 1 - avaliação } \\
\text { micronível, focada nos } \\
\text { indivíduos e seus } \\
\text { comportamentos } \\
\end{array}$ & $\begin{array}{c}\text { Análise de impactos no } \\
\text { comportamento de grande } \\
\text { número de indivíduos. Ex.: } \\
\text { estudos demográficos }\end{array}$ \\
\hline & $\begin{array}{c}\text { Tipo } 2 \text { - avaliação } \\
\text { mesossocial focada nas } \\
\text { organizações e suas redes } \\
\text { sociais } \\
\end{array}$ & $\begin{array}{c}\text { Análise de impactos no } \\
\text { comportamento de atores } \\
\text { coletivos, como organizações } \\
\text { e movimentos sociais }\end{array}$ \\
\hline & $\begin{array}{l}\text { Tipo } 3 \text { - avaliação } \\
\text { macrossocial focada nas } \\
\text { relações nacionais e } \\
\text { internacionais }\end{array}$ & $\begin{array}{c}\text { Análise de impactos em } \\
\text { microssistemas sociais, tal } \\
\text { qual a política nacional ou } \\
\text { internacional, o sistema } \\
\text { legislativo, etc. }\end{array}$ \\
\hline 素 亏 & Modo de vida das pessoas & Como vivem e trabalham \\
\hline
\end{tabular}




\begin{tabular}{|c|c|c|}
\hline & Cultura & $\begin{array}{c}\text { Costumes, valores e } \\
\text { convicções }\end{array}$ \\
\hline & Comunidade & $\begin{array}{l}\text { Coesão, estabilidade, } \\
\text { característica dos serviços e } \\
\text { facilidades }\end{array}$ \\
\hline \multirow{5}{*}{ 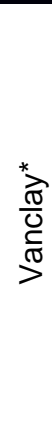 } & Sistema político & $\begin{array}{c}\text { Democracia/gestão dos } \\
\text { recursos }\end{array}$ \\
\hline & Ambiente & $\begin{array}{c}\text { Qualidade do ar, } \\
\text { disponibilidade de alimentos }\end{array}$ \\
\hline & Saúde e bem-estar & $\begin{array}{c}\text { Bem-estar psicológico e } \\
\text { mental }\end{array}$ \\
\hline & $\begin{array}{l}\text { Direitos pessoais e de } \\
\text { propriedade }\end{array}$ & Violação das liberdades civis \\
\hline & Medos e aspirações & $\begin{array}{c}\text { Percepção sobre segurança, } \\
\text { medos e aspirações para o } \\
\text { futuro da comunidade e de } \\
\text { seus filhos }\end{array}$ \\
\hline
\end{tabular}

* Vanclay (2002) apresenta outra série de variáveis e indicadores para a avaliação de impacto social.

É fato que não há, ainda, uma metodologia consensual para a avaliação de impacto social (AIS). Vanclay (2002) vê isso como fruto da deficiência de uma agência reguladora da definição de AIS e de uma revisão séria para nortear o profissional na melhoria de sua prática. Consensos sobre a definição de AIS e uma indicação genérica sobre as variáveis mínimas necessárias poderiam aumentar a qualidade dos estudos (VANCLAY, 2002, p. 189, tradução nossa).

No Brasil, algumas experiências vêm sendo realizadas no sentido de propor refletir e criar suporte teórico-metodológico para avaliar os impactos sociais em seus diferentes âmbitos e setores produtivos. Cabe ressaltar que a dimensão social começa a ter relevância a partir das metodologias de avaliação de impacto ambiental, preocupação latente da sociedade contemporânea. Nesses casos, a dimensão social sempre foi considerada essencial nos indicadores de sustentabilidade.

Yeganiantz e Macêdo (2002) realizaram estudos buscando avaliar os impactos sociais decorrentes do uso de tecnologias agropecuárias. Os autores ressaltam a carência de uma metodologia científica para avaliar "tanto ex ante como ex post as implicações sociais, econômicas e ambientais das novas tecnologias que não cabem dentro da análise socioeconômica convencional que exclui as 
externalidades tanto positivas quanto negativas" (YEGANIANTZ; MACÊDO, 2002, p. 8).

Outro estudo é a Pesquisa de Condições de Vida (PCV), concebida no final da década de 1980 e desenvolvida pela Fundação SEADE. Os objetivos visavam suprimir a ausência de fonte primária de dados sobre as características demográficas e socioeconômicas, consideradas determinantes para a compreensão das condições de vida da população das regiões metropolitanas e aglomerações urbanas não metropolitanas de maior concentração em São Paulo (COSTA, 2003). Dados que pudessem monitorar as mudanças nas variáveis demográficas e socioeconômicas foram utilizados, nessa pesquisa, para averiguar a magnitude e a distribuição da pobreza urbana.

Ainda sobre qualidade de vida, cita-se o Índice Paulista de Responsabilidade Social (IPRS), criado em $2000 \mathrm{com}$ o intuito de estimar o desenvolvimento e a qualidade de vida dos municípios paulistas. A proposição colocada baseava-se na premissa de que a "mensuração da qualidade de vida pressupõe considerar vários aspectos não transferíveis entre si", ou seja, nenhuma dimensão poderia substituir outra, nem hierarquizá-las (TORRES et. al., 2003, p. 83). Para tanto, o SEADE passou a considerar a qualidade de vida como multidimensional, e isso representou dois problemas: o primeiro refere-se ao fato de que não existe uma teoria universal que indique quais componentes são essenciais para a mensuração da qualidade de vida; o outro é que a multidimensionalidade implica tornar impossível a elaboração de um único indicador ordenável de condições de vida. Como alternativa, o estudo partiu para a criação de uma "tipologia que permita distinguir as diferentes situações que configuram as condições de vida de uma população" (TORRES et al., 2003, p. 83).

Considerar a qualidade de vida em uma abordagem multidimensional parece ser uma aproximação interessante e prática para analisar o caso das agroindústrias familiares rurais. Em primeiro lugar, permite explorar as interações entre as variáveis e entre seus indicadores, favorecendo uma análise sistêmica, mas também se enfrentam as problemáticas postas pelos autores ao analisar o caso do IPRS (TORRES et al., 2003).

Nesse sentido, Vanclay (2002) sugere a separação dos processos de mudança social daqueles que são variáveis de impacto social. Para tanto, o autor sugere, com ressalvas, uma "lista simples e indicativa como exemplo de processos de mudança social" 
(VANCLAY, 2002, p. 193, tradução nossa), composta pelos seguintes agrupamentos ${ }^{4}$ : processos demográficos (mudanças no número e na composição da população); processos econômicos (como as pessoas ganham a vida e exercem atividades econômicas na sociedade); processos geográficos (mudanças no uso da terra); processos legais e institucionais (eficiência e eficácia das estruturas institucionais, incluindo as governamentais e não governamentais); processos de emancipação e empoderamento (influência crescente nos processos de tomada de decisão); processos socioculturais (cultura da sociedade); outros processos.

Para impacto social, Vanclay (2002) propõe uma lista com sete categorias, a fim de contribuir para a reflexão sobre as possibilidades de impacto. Aliás, o autor reforça questões como a importância de que a lista seja ampla, tendo em vista que impactos sociais abrangem uma grande variedade de questões ${ }^{5}$ : (A) Indicadores de Impactos na Saúde e Bem-Estar Social; (B) Indicadores de Impactos na Qualidade do Ambiente Vivido; (C) Indicadores de Impactos Econômicos e de Bem-Estar Material; (D) Indicadores de Impacto Cultural; (E) Indicadores de Impacto na Família e na Comunidade; (F) Indicadores de Impacto no Ambiente Institucional, na Legislação, na Política e na Equidade; (G) Indicadores de Impacto nas Relações de Gênero.

A partir dessas considerações e tomando-as como norteadoras, segue-se a reflexão sobre a dimensão social no universo da agroindústria familiar rural.

\section{A DIMENSÃO SOCIAL DA AGROINDÚSTRIA FAMILIAR RURAL}

No intuito de sondar alguns indicadores que podem ser utilizados para avaliar o impacto social nas AFRs, destaca-se de imediato a necessidade de pensar em uma relação escalar: os

\footnotetext{
${ }^{4} \mathrm{Na}$ obra, o autor analisa, para cada grupo, um conjunto de indicadores que podem Intluenciar as mudanças sociais.

${ }^{5}$ Vanclay (2002) coloca que os impactos sociais (isto é, todos os impactos nos seres humanos) são sentidos ao nível de um indivíduo, outros ao nível da unidade familiar ou doméstica, outros pelas organizações sociais, instituições, ou comunidade, etc. Alguns, ainda, são físicos, outros são perceptivos ou emocionais. Alguns impactos podem até estar além da população, como no meio físico, mas ainda assim são impactos sociais.
} 
efeitos da consolidação de uma AFR têm consequências diretas, indiretas e difusas no espaço-tempo, ou seja, refletem diretamente na dinâmica do espaço social em que estão inseridas (social, econômico, político e ambiental).

Ao sistematizar experiências de adoção de tecnologias agropecuárias, Yeganiantz e Macêdo (2002, p. 11) também ressaltam que o impacto social, econômico e ambiental envolve não só os que adotam a tecnologia, mas também todas as instituições e ambientes onde os resultados da pesquisa estão presentes. Além disso, os impactos sociais positivos têm a capacidade de gerar estímulos para a expansão da adoção das tecnologias em outros sistemas produtivos.

$\mathrm{Na}$ análise de pesquisas, programas e/ou projetos sobre a agroindustrialização, percebe-se a ampla ênfase dada a questões como a melhoria da qualidade de vida e do bem-estar social, promovidas em função da "inserção" de uma AFR em dada realidade. Como já alertou Vanclay (2002), seria suficiente considerar qualidade de vida e bem-estar social como os impactos sociais que podem ser atribuídos à AFR? Quais poderiam ser as demais variáveis e indicadores, a fim de buscar uma avaliação de impacto social de forma mais ampla?

Ao avaliar o nível de "qualidade de vida", Torres et al.(2003) acrescentam que uma das dificuldades se refere ao "como fazê-lo", seja quanto às informações a serem selecionadas ou aos critérios a serem utilizados. Mensurar a qualidade de vida implica, necessariamente, considerar diferentes aspectos para além das condições econômicas, como informações sobre saúde, conhecimentos e habilidades, relações sociais, condições de trabalho, qualidade dos serviços médicos, educação, dentre outros. Apesar de se constituir um processo em construção, muitas dessas variáveis já são consideradas, pelo menos indiretamente, quando se analisa, detalhadamente, os discursos em torno da AFR.

Dentre as iniciativas pioneiras no estudo da AFR, algumas delas já apontavam para os potenciais na geração, direta e indireta, de novos postos de trabalho e de renda aos agricultores familiares, promovendo a sua (re)inclusão social e econômica (PREZOTTO, 1997). Essa seria, portanto, uma das atividades com capacidade de reversão das consequências ${ }^{6}$ do processo de modernização da

${ }^{6}$ Leia-se impactos negativos sociais e ambientais. 
agricultura. A partir de meados da década de 1990, a AFR passou a ser considerada uma das atividades capazes de promover 0 desenvolvimento rural sustentável, através do "(re)início da construção da cidadania, bem como da oportunidade de resgate de valores e saberes" (PREZOTTO, 2002, p. 138).

No estudo realizado por Wesz Junior $(2006)^{7}$, observa-se uma série de impactos gerados a partir da consolidação de agroindústrias familiares. O autor analisa o uso da mão de obra familiar, o caráter artesanal da produção, a diversificação na linha de produção ${ }^{8}$, a agregação de valor e as relações de proximidade e de confiança entre produtor e consumidor, que conferem competitividade e legitimação dos produtos junto à sociedade:

Mas, além de trazer renda e qualidade de vida para os dependentes deste processo, a agroindustrialização rural começa a ser reconhecida como uma atividade que segura o agricultor no seu espaço de origem, além de fomentar toda a economia local, pela relação de proximidade que existe tanto na contratação de mão-de-obra como no fornecimento da matéria prima pelos vizinhos, bem como, na comercialização dos produtos, que se realiza numa escala estreitamente regionalizada (WESZ JR., 2006, p. 25).

A relação de proximidade pode ser demarcada pela significativa interação na circulação de matérias-primas e produtos (como a própria mão de obra) entre as unidades produtivas agrícolas na escala local (comunidade) ou regional. Nesse sentido, Vieira (1998) também reforça o papel "social" da agroindústria familiar e a

\footnotetext{
${ }^{7} \mathrm{O}$ estudo tomou por objeto as agroindústrias familiares que trabalhavam com derivados de cana-de-açúcar (melado, cachaça, licores, mandolate, açúcar mascavo) nas microrregiões de Santa Rosa, Santo Ângelo e Cerro Largo, no Estado do Rio Grande do Sul. Como objetivo, buscou caracterizar as propriedades que tinham agroindústrias familiares e visualizar se a pluriatividade (como o processamento) acabava por fortalecer ou por desestimular a perda de vínculos e semelhanças com a agricultura familiar monoativa.

8 "Geralmente quem produz cachaça também faz licor, quem faz melado ainda produz açúcar e rapadura e quem se ocupa com esse último aproveita para fazer mandolate. Desta forma, essas estreitas ligações entre os produtos acabam por dinamizar grande parte das propriedades (...)" (WESZ JR., 2006, p. 44).
} 
importância de fomentá-la como uma estratégia para a geração de empregos:

Pela sua importância social, como fonte geradora de empregos em um ambiente cada vez menos intensivo em mão-de-obra e como fator de interiorização, interessa, porém, criar condições para a constituição e o desenvolvimento da agroindústria familiar de pequena escala, seja ela urbana ou rural (VIEIRA, 1998, p. 13).

Ao analisar sob o foco da verticalização ou de agregação de valor, Wilkinson (2000) destaca alguns elementos que contribuíram para o desenvolvimento e a considerável expansão da atividade no espaço rural, como a miniaturização tecnológica, a segmentação de mercados e a persistência de mercados de proximidade ${ }^{9}$. As consequências dessa expansão podem ser visualizadas na elaboração de políticas específicas (WILKINSON, 2000) para as AFRs, dentre elas o PRONAF Custeio/Investimento - linha especial Agroindústria Familiar.

Além desses, há outros trabalhos que vêm atentando para algumas especificidades da AFR, como as relações de confiança produtor-consumidor como garantia da "qualidade artesanal" (ZIMMERMANN, 2006); a importância do reconhecimento do saberfazer, por parte do consumidor, para uma otimização na agregação de valor aos produtos artesanais (GÓMEZ; BOUCHER; REQUIERDESJARDINS, 2006); a concentração geográfica de algumas atividades em função de determinada identidade territorial, que acaba por contribuir para um processo de especialização produtiva do espaço, através da geração de um ambiente de qualificação da mão de obra, relações de confiança, difusão do conhecimento técnico (REQUIER-DESJARDINS, 1999; SILVEIRA et al., 2008); as relações de gênero (BONI, 2006; MALUF, 1999); os efeitos da descentralização agroindustrial como fator dinamizador da economia local (MALUF, 1999), aproveitando a base familiar e a tradição no

\footnotetext{
${ }^{9}$ Um dos possíveis motivos para a persistência de mercados de proximidade coloca em evidência a busca por relações de confiança entre produtor-consumidor, que tomam por base a inexistência de riscos alimentares (SILVEIRA, 2006), percepção que dota os consumidores dos produtos com atributos "coloniais" de uma imunidade subjetiva (GUIVANT, 1994).
} 
processamento de alimentos e/ou bebidas; as limitações colocadas pelo ambiente institucional para legalização (GUIMARÃES, 2001); o controle de qualidade e as exigências legais como um espaço para a construção de ações sob uma abordagem socioambiental (SILVEIRA; HEINZ, 2005; SILVEIRA; GUIMARÃES, 2007).

Ao acompanhar o processo de constituição de AFRs, Duarte e Grigolo (2006) elaboraram uma coletânea que apresenta as reflexões dos agricultores familiares sobre suas práticas baseadas na vivência familiar, associativa, agroindustrial e comunitária. Os autores atentam para a importância de entender qual é a concepção e o papel da agroindústria para a agricultura familiar "enquanto parte da diversidade e da policultura" das unidades de produção agrícola e da vida familiar, em contraponto com a "noção de agroindústriaempresa", que transforma o agricultor em empresário, subordinando0 aos ditames do mercado (DUARTE; GRIGOLO, 2006, p. 5).

Essa discussão - nem sempre presente - é pertinente, já que um significativo conjunto de AFRs, após a legalização, acaba por ser "engolido" pela lógica mercantil. Um dos exemplos desse processo é a autoexploração da força de trabalho familiar. Afinal, a reflexão posta por Duarte e Grigolo parece tocar uma questão fundamental: "E viável para a agricultura familiar um tipo de agroindústria que exija dedicação exclusiva?". Nessa questão, estão postas algumas faces dos limites da AFRs e, possivelmente, dos seus impactos negativos, principalmente nas escalas da vida familiar e da unidade de produção ${ }^{10}$.

Por final, para o Programa de Agroindustrialização da Produção da Agricultura Familiar 2007-2010, a agroindústria familiar "pode favorecer um modelo de desenvolvimento rural sustentável", especialmente nos municípios pequenos, e aponta como consequência imediata $\mathrm{o}$ "surgimento e/ou fortalecimento do comércio local, estimulado pelo aumento no consumo" de bens não duráveis e duráveis (como aqueles usados na produção e no processamento da AFR) (MINISTÉRIO DO DESENVOLVIMENTO AGRÁRIO, 2008, p. 10).

\footnotetext{
${ }^{10}$ Os trabalhos de Silveira e Heinz (2005) e Silveira e Guimarães (2007) analisam com propriedade as consequências que a aplicação da legislação traz para as AFRs. Aliás, Silveira e Guimarães (2007) dedicam-se, também, a apontar os limites das políticas públicas quando não atentam para a delimitação do público-alvo, em especial nesse tipo de atividade onde a diversidade é tão ampla.
} 
Dentre os atributos considerados pelo relatório "PRONAF Agroindústria 2003-2006" para a avaliação do desempenho do programa estão: 0 número de famílias beneficiadas, as agroindústrias criadas, os empregos gerados no setor primário e no agroindustrial, o acréscimo de renda, o crédito rural aplicado e os treinamentos realizados (técnicos e produtores), os manuais técnicos, os perfis agroindustriais, os seminários e as feiras. Esses indicadores podem traçar um panorama genérico do alcance do programa, mas são insuficientes para captar as mudanças sociais decorrentes das ações desenvolvidas e das atividades que, de fato, foram implementadas.

A partir dessas análises, lançamo-nos ao desafio de selecionar e testar algumas variáveis sobre a dimensão social da agroindustrialização, discutidas a seguir.

\section{OS IMPACTOS SOCIAIS OBSERVADOS NA ESCALA DA UNIDADE DE PRODUÇÃO FAMILIAR}

Apresentamos alguns dos impactos diagnosticados na escala da unidade de produção familiar e no grupo familiar, tendo em vista as mudanças que aconteceram em função do processo de agroindustrialização.

Os principais impactos observados foram na garantia de manutenção e de reprodução econômica e social da unidade de produção e do grupo familiar. Tanto no caso da produção artesanal (casos informais), como nas AFRs (casos formais) ${ }^{11}$, a geração de renda aparece como um impacto capaz de desencadear outros ou que, ao menos, promove articulação entre as outras variáveis: renda, educação, saúde e aquisição de infraestruturas (domésticas e para propriedade). Há, sem dúvida, mudanças qualitativas com o acréscimo na renda familiar ${ }^{12}$, em especial nas condições de vida do grupo familiar.

\footnotetext{
${ }^{11}$ Cabe reforçar que, nas agroindústrias familiares visitadas, mesmo com o incremento de tecnologia e infraestrutura específicas, os grupos familiares envolvidos conseguiram manter parte do caráter artesanal de seus produtos, representado, principalmente, pela manutenção da receita familiar, do trabalho familiar e de alguns procedimentos de processamento.

${ }_{12}$ Houve significativa dificuldade para estimar os valores ou então os percentuais de acréscimo na renda familiar. Houve casos em que os agricultores não se sentiram à vontade para falar sobre a questão da renda e outros em que tiveram dificuldade para
} 
Portanto, o incremento de renda foi um dos indicadores mais destacados quando o assunto se refere às mudanças vividas em função da agroindústria familiar rural. Mesmo havendo outros impactos, a renda se destaca como uma das variáveis mais significativas e, também, a primeira a ser lembrada. Em quatro dos seis casos estudados, a agroindústria deixou de ser uma atividade com caráter "complementar" para tornar-se a principal atividade da propriedade. Porém, também teve reflexo direto na forma de ocupação da força de trabalho familiar: ao indagar um dos agricultores envolvido com a agroindústria de cana-de-açúcar sobre as mudanças em relação à ocupação da força de trabalho, ele nos respondeu: "[...] ocupou mas e bota ocupar nisso [...] a gente trabalha 8 horas por dia, antes no inverno trabalhava em casa, mas não tinha muito serviço" (AG01V, 2008). Essas são mudanças fundamentais e que exigem uma reorganização da estrutura produtiva, da dinâmica em torno da distribuição do trabalho e, sem dúvida, do modo de vida rural.

Além disso, as perspectivas com incremento de renda são uma das principais motivações tanto para a permanência como para o retorno de jovens à propriedade familiar. Entre as seis AFRs visitadas, há cinco jovens envolvidos diretamente no processo de produção. Portanto, renda e trabalho são duas variáveis que, quando associadas, abrem novos horizontes. As observações a campo permitiram comprovar que, em todas as agroindústrias, houve contratação temporária, seja de terceiros oriundos do espaço urbano, seja de familiares e pessoas conhecidas da vizinhança. É importante destacar que, no âmbito da agroindustrialização, por tratar-se de uma atividade com certa regularidade (outra lógica produtiva), não foram observados casos em que as famílias se utilizavam da estratégia de "troca de serviços" com vizinhos.

No caso da produção artesanal, a geração de emprego não é aplicável, pois o trabalho extra com a atividade de processamento implica um aumento da jornada, já que não substitui, mas complementa as demais atividades ${ }^{13}$. Além disso, esse perfil produtivo geralmente é sazonal ${ }^{14}$ ou esporádico e é associado às

expressar em valores monetários o quanto houve de alteração. Em um dos casos, o grupo familiar sugeriu um acréscimo de $200 \%$ na renda da família.

${ }^{13}$ Não significa que isso não ocorrem outros casos. No entanto, na produção artesanal, a própria falta de infraestrutura adequada acaba por exigir maior tempo de trabalho/dedicação.

${ }^{14}$ Como a produção de vinho ou de cachaça - são duas atividades que ocorrem em 
atividades consideradas "domésticas" desenvolvidas pelas mulheres na propriedade. A renda adicional, em regra, é destinada para a aquisição de bens de consumo e outras utilidades que venham a satisfazer as necessidades básicas do grupo familiar.

No caso das agroindústrias, a geração de renda também implicou a diferenciação social na comunidade, em especial quando há intervenção com recurso público, conforme comenta um agricultor: "[...] tem uns invejosos! Tem um pessoal que achou que nós ganhamos tudo de graça [...] mas não sabem a conta que nós temos que pagar" (AG01V, 2008). Essa questão também foi levantada pelas lideranças locais:

Às vezes até dá inveja entre os vizinhos! Bom, porque aquele que tem agroindústria é que se destaca, tem mais renda, tem uma qualidade de vida melhor, consegue trocar de carro, consegue reformar a sua casa (pintando, reformando) [...] quem se doou mais para a agroindústria é quem mais tá ganhando renda hoje. [...] Tem até casos que até serviu para afastar [...] é que uma ou duas famílias ficaram mais de lado, mas o mais importante é que desafia as outras pessoas a estar buscando novas alternativas (AD01V, 2008, grifos nossos).

Poderíamos retomar nossa questão inicial aqui: o que significa ter uma "qualidade de vida melhor"? E sobre a associação direta de que qualidade de vida implica se "doar mais para a agroindústria", até que ponto a lógica produtiva da agroindústria, ao adentrar no mundo institucional e no mercado, não implica uma descaracterização do modo de vida das famílias rurais? O que motiva algumas famílias a "ficar mais de lado", ou mesmo seguir utilizando-se de estratégias tradicionais como a produção artesanal esporádica e como valor de troca? São questões para as quais ainda não temos respostas.

Os impactos da agroindustrialização têm várias dimensões, e considerar sobretudo a dimensão econômica nos impede de questionar outras consequências. Sem dúvida, ao promover a 
participação dos agricultores em outros circuitos e exigir novas habilidades, a agroindústria também contribui para processos de inserção social e política. Em um dos casos, dois sócios, além do trabalho junto à agroindústria, atuavam como lideranças municipais no sindicato dos trabalhadores rurais. Noutro caso, o agricultor deixou de exercer cargo de liderança, tendo em vista as diferentes concepções em torno do papel da cooperativa, fato que parece ter gerado um pouco de perda do prestígio e/ou sentimento de frustração.

A articulação e a organização das agroindústrias em forma de uma única entidade jurídica incitaram alguns sentimentos de diferença, tanto entre agroindústrias como com os demais agricultores. De forma geral, a diferenciação social parece ser inevitável, seja em seus impactos positivos, seja em seus impactos negativos; porém, a forma de administra-la depende muito das habilidades políticas daqueles agentes que participam desse universo. Cabe aqui um estudo mais detalhado, para compreender como o modo de vida e as rotinas sociais das famílias são alterados com a agroindustrialização.

Em seguida, mas de forma articulada, aparecem outras variáveis. $\mathrm{Na}$ educação, os indicadores de "frequência de participação em cursos", "visitas recebidas na propriedade" e "liderança política/articulação social" foram os mais representativos, comprovando a tese de que os agricultores envolvidos no processo de agroindustrialização têm forte tendência a destacar-se na comunidade, a expandir seu espaço social e a agregar diferentes conhecimentos.

A variável educação, na maioria dos casos, começou a sofrer as primeiras alterações (as quais nem sempre são percebidas pelos seus protagonistas), tendo em vista a participação em espaços de discussão, em visitas técnicas e em cursos voltados à administração das unidades, atividades que geralmente ocorrem ainda antes da elaboração dos projetos agroindustriais e que também permitem a troca de experiências. Os espaços permanentes de formação e qualificação são fundamentais nesse processo, como mostra um depoimento entusiasmado de uma idosa que participa do processo de produção: "Até eu fiz um curso, são bons! Eu gostei muito. [...] lá em Casca [RS] ficamos oito dias, até o diploma ganhei lá! 'De nova' a gente não teve oportunidade de estudar, depois 'de velha' eu consegui fazer curso" (AG05.2S, 2008). Este outro relato demonstra um pouco a sobrecarga com opções de cursos: "Depois 
que nós começamos a agroindústria, o que apareceu de curso, se fosse fazer tudo, não estaria aqui [...]" (AG01.2V, 2008).

Enquanto a participação em atividades fora da unidade de produção é relatada com entusiasmo e, principalmente, reconhecida como espaço importante para adquirir novos conhecimentos, isso não ocorre naquelas UPAs que mantêm sua lógica de produção artesanal de alimentos. O produtor artesanal, enquanto mantém sua lógica de produção, com pequena escala e esporádica, não é considerado pelas políticas públicas, a não ser como um sujeito oculto que pode comprometer a saúde pública ${ }^{15}$, ou, ainda, no senso local, é considerado como um concorrente aos produtos legalizados das agroindústrias, com certa estigmatização.

As variáveis que apresentaram maior dificuldade para detectar mudanças ${ }^{16}$ foram saúde, comunicação e energia. Em geral, os entrevistados destacaram que houve melhorias nas condições de trabalho graças à aquisição de equipamentos tecnológicos (seja na AFR ou na lavoura) e, por isso, supostamente trabalham menos afinal, como eles mesmos dizem: o "serviço" melhorou "[...] 100\% porque estamos na sombra" (AG06S) ou, noutro caso, "[...] dava muito mais serviço eles fazer o queijo lá na pia e no fogão do que na agroindústria" (AG03L). Os acréscimos na renda proporcionaram alguma facilidade no acesso a serviços de saúde (principalmente em caso de emergências), além de sentimentos positivos e boas perspectivas quanto ao futuro, verificados através das estimativas de reformas na agroindústria e aumento da produção. Já a variável comunicação também não sofreu grandes alterações, exceto aquelas vinculadas à educação (ampliação das relações sociais). Um fato que contribui nesse sentido é a fluidez com que as tecnologias de comunicação têm chegado ao espaço rural, como é o caso do telefone celular e da internet ${ }^{17}$.

\footnotetext{
${ }^{15}$ Como já foi destacado, não seria momento oportuno reconhecer as redes informais de comercialização como fundamentais para garantir a reprodução dos grupos familiares e, assim, possibilitar um processo de qualificação da produção artesanal, uma qualificação que se proponha, inclusive, a reconhecer seu caráter artesanal e preocupe-se em mantê-lo? Para tal, poder-se-ia utilizar estratégias como a validação social dos produtos. ${ }^{16}$ Nessas variáveis, geralmente, as mudanças tendem a ocorrer progressivamente, em um longo espaço de tempo, fato que dificulta a sua percepção pelos sujeitos envolvidos no processo.

${ }^{17}$ No entanto, no universo de estudo, as AFRs não tiveram significativa participação nesses casos. Geralmente, são questões ligadas a processos externos (ações da prefeitura municipal e empresas privadas).
} 
No caso da energia elétrica também não foram observadas mudanças em função da AFR.Isso se deve, em parte, aos programas que vêm sendo desenvolvidos no município de Constantina, em uma parceria entre o Sindicato dos Trabalhadores Rurais (STR) e a Cooperativa de Crédito Rural com Interação Solidária (CRESOL), como o Programa Luz para Todos ${ }^{18}$, que permitiu a realização de reparos e a instalação de redes de transmissão no município.

Fato semelhante foi observado na variável habitação: grande parte das moradias rurais foram reformadas através do Programa Habitação Rural. Mesmo assim, nessa última variável, as AFRs tiveram uma singela participação, já que o programa exige uma parcela de contrapartida por parte dos beneficiados contrapartida esta que só se tornou viável em função da renda proveniente da agroindústria. Novamente, a questão da geração de renda acaba aparecendo como um elemento propulsor de melhorias nas infraestruturas da UPA e para o grupo familiar, como podemos acompanhar nestes dois relatos: "Reformas, acho que todos fizeram. Um pouco foi ajuda da Cresol também, mas tem que dar contrapartida [...] todo mundo reformou!" (AG01V, 2008); "Foi melhorada a casa, in! Foi concluída estrebaria nova, foi feita garagem, comprado ordenha, até casei (risos)" (AG03L, 2008). Há, ainda, a avaliação de que a renda proveniente da agroindústria "Ajudou, com certeza, reformas da casa, pintura [...]" (AG06S, 2008).

Por fim, na variável lazer, também foram observadas mudanças significativas, mas poucas estão vinculadas à AFR. Dentre as colocações, a progressiva diminuição da população rural inviabilizou algumas atividades que antes eram tradicionais, como os times de futebol de campo e os campeonatos municipais. De qualquer forma, "cada um tem um lazer (risos), tem gente que vai pescar, caçar, outros vão jogar bola..." (AG01V, 2008).

Da mesma forma que a geração de trabalho e de renda aparecem muito próximas, as variáveis autonomia e acesso a recursos também apresentaram o mesmo comportamento: ao passo que a agroindústria passa do nível de atividade complementar para atividade principal da propriedade, observa-se uma autonomia da

\footnotetext{
${ }^{18}$ O Governo Federal iniciou em 2004 o Programa Nacional de Universalização do Acesso e Uso da Energia Elétrica - Luz para Todos, com o objetivo de levar energia elétrica para a população do meio rural. O programa é coordenado pelo Ministério de Minas e Energia, com participação da Eletrobrás e de suas empresas controladas. A ligação da energia elétrica até os domicílios é gratuita (MME, 2009).
} 
propriedade e a busca por novos recursos, a fim de implementar melhorias tecnológicas. No entanto, da mesma forma, essa progressiva autonomia é relativa, uma vez que passa a depender de matéria-prima e das condições de mercado. No entanto, foi unânime a preocupação com investimentos que não comprometessem a capacidade de pagamento da propriedade rural. Ainda na variável acesso a recursos, com a participação na cooperativa (COOPERAC), as agroindústrias têm a possibilidade de participação em feiras/exposições.

Em contraponto às tradicionais discussões de gênero que colocam em questão o trabalho da mulher no espaço rural, nas unidades visitadas, observou-se que a divisão de trabalho oportuniza serviço a todos e tem por especificidade o tipo de linha de produção. Nas agroindústrias, as mulheres estão inseridas no processo de produção: no caso dos embutidos de suínos e derivados de leite, elas trabalham lado a lado, exercendo as mesmas funções que os homens; no caso do processamento de cana-de-açúcar, às mulheres cabe acompanhar as caldeiras durante o processo de produção do açúcar mascavo e, depois, ficam responsáveis por embalar e rotular os produtos. Já no caso da produção artesanal, o trabalho é predominantemente feminino, desde a ordenha até a produção dos queijos.

A participação dos jovens também sofreu alterações, já que três jovens voltaram para atuar junto às agroindústrias e, em outro caso, um jovem casal permaneceu na propriedade. Ao falar das mudanças, um dos jovens destacou: "Bom, eu, se não tivesse a agroindústria, tinha ido trabalhar para fora!" (AG01.5V, 2008).

Enquanto isso, a participação dos idosos esteve presente em quatro das seis unidades visitadas. Em geral, eles participam das atividades de processamento, quando não as coordenam, como foi um dos $\operatorname{casos}^{19}$. No caso dos embutidos, a idosa relembra da produção artesanal de salame colonial, antes de estruturar a agroindústria: "Nós fazíamos ali, no porão, tudo aberto, nós tinha um porão bom! Daí carneava lá em baixo [...] trazia para dentro e fazia. Depois veio o matador daí nós compramos lá [...] nós compramos o porco vivo, levamos lá no abatedor daí eles trazem a carne em casa" (AG05.2S, 2008).

\footnotetext{
${ }^{19}$ Aliás, a inspiração para o nome fantasia da agroindústria veio do nome da "mãe", que fazia os queijos de forma artesanal na cozinha doméstica e tinha um sonho, compartilhado com o esposo, de montar algum empreendimento.
} 
A variável gênero demonstrou, através dos indicadores, a plena inserção de todo o grupo familiar nos processos de produção, seja de jovens ou de idosos, seja na produção da matéria-prima, no processamento ou na comercialização. A união do grupo familiar em torno da atividade se coloca como um impacto social significativo. Infelizmente, a proposta da pesquisa e o método de trabalho de campo não permitiram aprofundar e adentrar outras questões, tal qual o processo de tomada de decisão, gestão, comercialização, entre outras atividades geralmente vinculadas à figura masculina.

Essas questões influenciaram as relações do grupo familiar, sendo unânime a avaliação de que a AFR reforçou laços familiares. Esse fato foi observado inclusive na experiência da associação: "Melhorou trabalho em equipe, está mais unido, antes cada um pensava por si" (AG01.2V, 2008).

Quanto à segurança alimentar, não se pôde observar, diretamente, mudanças. Como foi possível diagnosticar, nos casos visitados em que as atividades não tomam todo o tempo das famílias e ainda incrementam a renda familiar, não haveria motivos para diminuir a diversidade de alimentos produzidos (na horta) ou então para a sua aquisição. No entanto, essa é uma questão que ficará aberta para futuras pesquisas.

Por fim, cabe algumas considerações sobre o conjunto de variáveis e indicadores. Através da correlação, podem-se identificar as variáveis que demonstram os principais elementos que sofrem mudanças com o processo de consolidação da agroindústria. Enquanto isso, nem todos os indicadores corresponderam ou puderam ser levantados a campo, especialmente aqueles com sentido mais subjetivo e/ou pessoal ou então que se referiam a questões monetárias das propriedades, difíceis de diagnosticar.

Algumas hipóteses levantadas sobre impactos positivos e negativos não foram observadas nos casos analisados. Em muitos desses casos, são questões que adentram o universo pessoal ou psíquico dos indivíduos. Por exemplo, na variável educação tinha-se por hipótese um efeito negativo, que seria a formação de um saber egoísta e autoritário ou então de fobia social, o que não foi observado a campo. Isso não significa que esses efeitos não aconteçam (ou, ao menos, tenham existido).Pelo contrário, as pessoas podem não se sentir à vontade para falar sobre isso, e, da mesma forma, os agentes locais podem até perceber, mas dificilmente haveria a possibilidade de atuar nessas situações. Para diagnosticar esses casos mais específicos, mas que são de 
fundamental importância na avaliação de impacto social, seria necessário um estudo etnográfico.

De qualquer forma, as variáveis que apresentaram mudanças mais significativas foram: trabalho, renda, educação, diferenciação social, acesso a recursos, gênero, consumo e grupo familiar. Depois dessas, estavam saúde, habitação, tempo e autonomia. As que sofreram menor alteração em função da agroindústria foram energia, transporte e comunicação. A variável segurança alimentar não pôde ser observada a campo, tendo em vista o método de trabalho utilizado (de visitas às unidades/famílias). Para detectar mudanças na variável segurança alimentar, seria ideal vivenciar a rotina familiar por alguns dias e, assim, construir uma relação mais próxima com o ambiente doméstico e o próprio ritmo/estilo de vida da família. Aliás, nessa linha, poder-se-ia facilitar o processo de observação e compreensão dos impactos sociais no grupo familiar, questão que ficará aberta para futuras pesquisas.

Além disso, sugere-se a inclusão da variável tempo de trabalho e que ela considere também a penosidade das atividades produtivas internas (UPA), usando para tanto 0 indicador "distribuição do tempo de trabalho" disponível. Diferentes trabalhos apontam para a necessidade da (re)organização da divisão do trabalho na UPA com o início da atividade de processamento (SANTOS, 2006; WESZ JR. 2006; SULZBACHER, 2007). Seguindo a lógica econômica, dedica-se mais tempo àquelas atividades que têm maior capacidade de gerar renda e isso gera, paulatinamente, o abandono de outras em função do uso intensivo da força de trabalho em uma atividade. Além disso, nessa variável, cabe refletir sobre o tempo dedicado a cada atividade, de acordo com o gênero e a faixa etária. Dessas correlações, pode-se observar a inserção dos jovens e das mulheres em cada atividade. Outra variável possivelmente importante é o "consumo", pois permite indicar as alterações no acesso e na frequência em que a família passa a adquirir bens de consumo, sejam esses duráveis (móveis e imóveis) como não duráveis (alimentos, roupas, etc.). 


\section{UMA PORTA ABERTA: POUCAS CONCLUSÕES E MUITAS PERGUNTAS SOBRE OS IMPACTOS SOCIAIS DAS AGROINDÚSTRIAS FAMILIARES RURAIS}

Podemos concluir que as potencialidades de gerar impactos sociais estão demarcadas na capacidade de promover a integração dos setores e das entidades locais em prol de estratégias que considerem a diversidade de atividades no espaço rural. Isso inclui também a recriação de atividades tradicionais na agricultura familiar e a inserção dos jovens e mulheres no processo de trabalho, promovendo novas perspectivas para sua permanência no espaço rural. Essas potencialidades têm relação direta com processos políticos na escala local, com capacidade de articulação dos diferentes agentes e de construção de projetos em comum.

Para a agroindústria constituir-se enquanto uma estratégia voltada ao fortalecimento da agricultura familiar, ainda é necessário avançar na compreensão de seu papel em cada unidade de produção, sobretudo na dimensão social. Ao longo da pesquisa, foi possível observar que há um ponto de equilíbrio de cada atividade para além dos cálculos de viabilidade econômica (os quais, em muitos casos, não existem). Esse ponto de equilíbrio é demarcado pela complexa relação entre disponibilidade de mão de obra versus matéria-prima envolvida no processamento, tendo em vista que geralmente há uma maior transferência de renda e maior exploração do trabalho familiar conforme o aumento da demanda. Outra lacuna é a produção de tecnologia voltada para a pequena escala de produção, ou mesmo tecnologias sociais, que pudessem aumentar a produtividade do trabalho familiar.

Dentre as possibilidades que poderiam favorecer a inversão desse processo, está a formação de redes de agroindústria, tanto para a comercialização como para a compra de insumos e/ou equipamentos, ou, ainda, uma articulação com agricultores do entorno da AFR para a produção de matéria-prima. Inevitavelmente, adentraríamos em um micro modelo de complexo agroindustrial, mas com a necessidade de construir relações produtivas e comerciais mais equitativas.

Também foi possível observar que, sejam positivos ou negativos, os impactos nem sempre são assim percebidos pelos sujeitos envolvidos no processo. Essa questão surge a partir da própria dificuldade de enumerar as mudanças que a agroindústria proporcionou. Assim, os impactos sociais negativos são mascarados 
pelos supostos benefícios da geração de renda, restando apenas algumas "impressões" sobre mudanças em relação à aceleração do ritmo de vida, do aumento de responsabilidades com o mundo do mercado e suas exigências, com a gestão do negócio, dentre outros. Reconhecer-se em outro tipo de vida e, principalmente, as consequências indesejáveis não é um fator positivo - pois se contrapõe à visão desenvolvimentista do agricultor empreendedor.

Tal aspecto merece atenção particular dos agentes envolvidos com extensão rural ou mesmo lideranças municipais e regionais. Percebe-se aí uma lacuna tanto em termos de monitoramento sobre o processo quanto sobre os objetivos - afinal, qual é o objetivo da agroindustrialização na propriedade familiar? Qual é o modelo de agroindústria e para qual realidade?

A agroindústria como o "carro-chefe" da unidade de produção gera um impacto considerável, porém pode comprometer a reprodução social. Se, por um lado, denota que os produtos das agroindústrias têm ganhado espaço no mercado (e os agricultores passaram a investir em escala), por outro lado, o aumento na escala de produção gera uma série de transformações na unidade de produção agropecuária. Em geral, a primeira delas é a redução de uma ou duas atividades para atender às demandas de trabalho e de produção para a agroindústria. Até que ponto é interessante ao agricultor familiar depender de uma atividade? Os projetos de desenvolvimento rural vislumbram agroindústrias familiares com característica artesanal ou com lógica industrial?

Concluindo, ao conceber-se a avaliação de impacto social como um processo de análise e gestão das consequências intencionais ou não intencionais no ambiente humano, cabe destacar que as principais mudanças observadas foram na segurança alimentar do entorno comunitário e na geração de renda e trabalho nas unidades de produção familiar. Ambas foram possíveis a partir do incremento de novos produtos no circuito de produçãodistribuição-consumo municipal. Sob o reverso da questão, as mudanças que geraram impactos negativos são sentidas principalmente por aqueles agricultores que se utilizam da produção artesanal de alimentos e/ou bebidas como uma estratégia para complementar renda, principalmente nos períodos de entressafra e/ou queda da produção.

Portanto, se, por um lado, a produção artesanal é que garante os impactos sociais positivos, à medida que se soma ao conjunto de atividades da unidade de produção e é "ativada" em 
seus momentos de crise, ela passa a sofrer determinadas restrições, sobretudo impostas pelo ambiente institucional. Essa é uma das consequências negativas, na avaliação de impacto social, da consolidação da agroindústria familiar rural. Ou seja, as estratégias tradicionais das famílias rurais podem implicar concorrência direta com os produtos das AFRs e, conforme o ambiente institucional, a estratégia de agroindustrialização pode se mostrar interessante para a unidade produtiva (AFR) em questão, mas pode ser, também, um fator de exclusão de um conjunto de agricultores que tinham na produção artesanal uma importante fonte de renda complementar. Inevitavelmente, a opção pela transição para a agroindústria familiar implica investimentos, mudanças na lógica de trabalho e de gestão da unidade de produção agrícola e, com elas, algumas consequências indesejáveis, que passam, muitas vezes, despercebidas (ou não são discutidas, compartilhadas) aos agentes envolvidos - sejam os agricultores, sejam as lideranças municipais ou mesmos os agentes vinculados ao trabalho de extensão rural.

No entanto, observamos que o movimento essencial nesse processo é a mudança da lógica produtiva na propriedade. De uma concepção de produção de matéria-prima, transita-se progressivamente a uma lógica que exige domínio sobre processamento, logística e comercialização. E essas são, geralmente, áreas que os agricultores não dominam, e muitos deles não têm interesse em dominar (preferem a tranquilidade da propriedade, a lida com a terra e com animais). A questão remanescente é: que perfil de agroindústria familiar seria de interesse a cada realidade municipal ou regional, tendo em vista a capacidade de gerar impactos sociais positivos?

\section{REFERÊNCIAS BIBLIOGRÁFICAS}

BECKER, L. Social Impact Assessment. European Journal of Operational Research, v. 128, n. 2, p. 311-321, jan. 2001. Disponível em: <www.elsevier.com/locate/dsw>. Acessado em: 28 maio 2008.

BONI, V. Agroindústrias familiares: uma perspectiva de gênero. In: XXX Encontro Anual da ANPOCS. Anais..., 2006, p. 01-25.

COSTA, O. V. Pesquisa de condições de vida. São Paulo em Perspectiva, São Paulo, v. 17, n. 3-4, p. 142-150, jul./dez. 2003. 
DUARTE, V. P.; GRIGOLO, S. C. Agroindústria associativa/familiar: o mito da viabilidade. Francisco Beltrão/PR: ADMR, 2006.

GÓMEZ, C. A. C.; BOUCHER, F.; REQUIER-DESJARDINS, D. ¿Cómo <<activar >> los sistemas agroalimentarios localizado en América Latina? Un análisis comparativo. In.: Revista Agroalimentaria, № 22, enero-junio, 2006. p. 17-27.

GUIMARÃES, G. M. A legislação industrial e sanitária dos produtores de origem animal: o caso das agroindústrias de pequeno porte. 2001. 146 f. Dissertação (Mestrado em Extensão Rural) - Universidade Federal de Santa Maria, Santa Maria, 2001.

GUIMARÃES, G. M.; SILVEIRA, P. R. C. da. Por Trás da Falsa Homogeneidade do Termo Agroindústria Familiar Rural: Indefinição Conceitual e Incoerências das Políticas Públicas In: ENCONTRO DA SOCIEDADE BRASILEIRA DE SISTEMAS DE PRODUÇÃO. 6. 2007.Anais... Fortaleza: SBSP, 2007. p. 01-20.

GUIVANT, J. Percepção dos Olericultores da Grande Florianópolis (SC) sobre os Riscos Decorrentes do Uso dos Agrotóxicos. Revista Brasileira de Saúde Ocupacional, São Paulo, v.82, n. 22, p.47-57, 1994.

MALUF, R. S. Ações públicas locais de apoio à produção de alimentos e a segurança alimentar. In: Polis Papers, n. 04, 1999. 43p.

Disponível

em:

$<$ http://www.polis.org.br/publicacoes_interno.asp?codigo=170>

Acesso em 23 de julho de 2009.

MINISTÉRIO DO DESENVOLVIMENTO AGRÁRIO (MDA). Secretaria da Agricultura Familiar. Programa de Agroindustrialização da Produção de Agricultores Familiares 2003/2006. Brasília, 2004.

Programa de Agroindustrialização da Produção da Agricultura Familiar 2007/2010. Documento referencial. Brasília, 2008.

MINISTÉRIO DE MINAS E ENERGIA. Programa Luz Para Todos. Disponível em: <http://www.mme.gov.br/programs_display.do?prg=8> Acesso 16 jan. 2009. 
MIOR, L. C. Agricultores familiares, agroindústrias e redes de desenvolvimento rural. Chapecó: Argos, 2005.

PREZOTTO, L. L. A agroindustrialização de pequeno porte: higiene, qualidade e aspectos legais. Revista Agropecuária Catarinense. Florianópolis. v. 10, n. 4, dez. 1997, p. 8-13.

Uma concepção de agroindústria rural de pequeno porte. Revista de Ciências Humanas, Florianópolis, n. 31, p.133-154, abr. 2002.

REQUIER-DESJARDINS, D. Agro-industria rural y sistemas agroalimentares localizados: ?Cuáles puestas?. In: ANIVERSÁRIO DE PRODAR. 10.2007. Anais... Quito, 1999. Disponível em: <http://www.prodar.org/cd.htm>.Acesso em: 10 ago. 2007.

SANTOS, J. S. Agroindústria familiar rural no Alto Uruguai do Rio Grande do Sul: uma análise do processo de comercialização. Dissertação (Mestrado em Agroecossistemas) Universidade Federal de Santa Catarina, Florianópolis, 2006.

SILVEIRA, P. R. C. da. Riscos alimentares em uma sociedade de risco: compreendendo o comportamento do consumidor de alimentos artesanais. Mensagem recebida por <prcs1064@yahoo.com.br> em 20 de dez. 2006.

SILVEIRA, P. R. C. da; GUIMARÃES, G. Gestão Ambiental em Espaços Rurais: do Imperativo Técnico a Construção Socioambiental - O Caso do Plano Diretor Urbano e Ambiental de Santa Maria/RS. In: ENCONTRO BRASILEIRO SOBRE SISTEMAS. 3. 2007.Anais... Florianópolis, 2007, p. 01-20.

SILVEIRA, P. R. C. da; HEINZ, C. Controle de qualidade normativo e qualidade ampla: princípios para reestruturação e qualificação da produção artesanal de alimentos. In: SEMINÁRIO SOBRE AGROINDÚSTRIA FAMILIAR E DESENVOLVIMENTO RURAL. 2005. Anais... São Luis Gonzaga: UERGS, 2005.

SILVEIRA, P. R. C. et al. Redefinindo riscos alimentares em sistemas agroalimentares localizados: o desafio da validação social da qualidade em mercados extra-regionais. n.: IV Congreso Internacional de la Red SIAL (ALFATER). Anais... Mar del Plata/Argentina: IICA, 2008b, p. 01-20. 
SULZBACHER, A. W. A agroindústria familiar rural enquanto alternativa para agricultura familiar: estudo de caso no município de Chapada/RS. Monografia (Curso de Geografia - Licenciatura Plena) Universidade Federal de Santa Maria, Santa Maria, 2007.

TORRES, H. da G. et al. Indicadores sociais: por que construir novos indicadores como o IPRS. São Paulo em Perspectiva, v. 17, n. 3-4, p. 80-90, 2003.

VANCLAY, F. Conceptualising social impacts. Environmental Impact Assessment Review, v. 22, p. 183-211, 2002. Disponível em: <www.elsevier.com/locate/eiar>. Acesso em: 28 maio 2008.

. Principles for social impact assessment: a critical comparison between the international and US document. Environmental Impact Assessment Review, v. 26, p. 3-14, 2006. Disponível em: <www.elsevier.com/locate/eiar>. Acesso em: 28 maio 2008.

. SIA principles: International Principles For Social Impact Assessment. Impact Assessment and Project Appraisal,v. 21, n. 1, p. 5-11, mar. 2003.

VIEIRA, L. F. Agricultura e Agroindústria familiar. Revista de Política Agrícola,v. 7, n. 1, p. 11-23, jan./mar. 1998.

WESZ JR., V. J. 0 perfil e a configuração estrutural das propriedades com agroindústrias familiares em nove municípios no noroeste gaúcho.2006. Monografia (Curso de Desenvolvimento Rural e Gestão Agroindustrial) - Universidade Estadual do Rio Grande do Sul, São Luiz Gonzaga, 2006.

WILKINSON, J. Distintos enfoques e debates sobre a produção familiar no meio rural. Agroecologia e desenvolvimento rural sustentável, Porto Alegre, v. 1, n. 3, jul./set, 2000.

YEGANIANTZ, L.; MACÊDO, M. M. C. Avaliação de Impacto Social de Pesquisa Agropecuária. Brasília: Embrapa Informação Tecnológica, 2002. Texto para discussão 13.

ZIMERMANN, S. A. Universo alimentar e qualidade do alimento: uma construção social. Rio de Janeiro: CPDA, 2006. 